\title{
CONSTITUCIONALISMO ALÉM DO ESTADO: PERSPECTIVAS HISTÓRICAS E DEMANDAS EMANCIPATÓRIAS
}

\section{CONSTITUTIONALISM BEYOND THE STATE: HISTORICAL PERSPECTIVES AND EMANCIPATORY DEMANDS}

\author{
HenRique Weil Afonso \\ Professor Permanente do Programa de Pós-graduação em Direito da Faculdade Damas da Instrução Cristã. Bacharel em Direito pela \\ UFJF. Mestre e Doutor em Direito pela PUC Minas. Atuou como Bolsista PNPD no Programa de Pós-gradução em Direito \\ Agroambiental da UFMT no período 2014-2015. \\ henriqueweil@hotmail.com
}

Thales Cavalcanti Castro

Professor Permanente do Programa de Pós-graduação em Direito da Faculdade Damas da Instrução Cristã. Bacharel e Mestre em Relações Internacionais pela Indiana University of Pennsylvania, EUA. Doutor em Ciência Política pela UFPE. Realizou estudos, após o doutorado, na Texas Tech University School of Law (1L) - 2005. É coordenador do curso de Relaçóes Internacionais da Faculdade Damas. É Assessor Internacional da Reitoria da Universidade Católica de Pernambuco. É cônsul da República de Malta em Recife e, atualmente, preside a Sociedade Consular de Pernambuco (SCP)Bacharel e Mestre em Relações Internacionais pela Indiana University of Pennsylvania, EUA. Doutor em Ciência Política pela UFPE. Realizou estudos, após o doutorado, na Texas Tech University School of Law (1L) - 2005. É coordenador do curso de Relações Internacionais da Faculdade Damas. É Assessor Internacional da Reitoria da Universidade Católica de Pernambuco. É cônsul da República de Malta em Recife e, atualmente, preside a Sociedade Consular de Pernambuco (SCP) TCCASTRO@HOTMAIL.COM

\section{RESUMO}

O objetivo deste trabalho é propor dois eixos de análise para o tema constitucionalismo global. Para sua concretização, privilegiou-se o estudo descritivo e analítico, por meio de pesquisa bibliográfica e documental. Inicia-se com uma discussão das principais correntes doutrinárias engajadas na temática (as Escolas Funcionalista, Normativa e Pluralista). Amparando-se na historiografia crítica do Direito Internacional, examina a produção de um discurso histórico apto a conciliar as contrastantes, ambivalentes e contextualizadas visões das relações jurídicas globais. Em sequência, dialogando com as abordagens do Terceiro Mundo para o Direito Internacional (TWAIL), problematiza a importância do constante exame dos processos coloniais e imperiais que não deve ser confinado nos referenciais clássicos da disciplina. Outras formas de organização social ou de arranjos constitucionais que podem ter sido ocultados ou deslegitimados ao longo dos últimos séculos. O trabalho conclui pela proposição de um engajamento crítico contínuo com a história, o colonialismo e o imperialismo, aberto ao diálogo e aos arranjos constitucionais menos evidentes.

Palavras-chave: Constitucionalismo Global; História do Direito; Teoria do Direito Internacional.

\begin{abstract}
The purpose of this survey is to propose two analytical axes to global constitutionalism. To accomplish the present research, the emphasis has been descriptive and analytical study, mainly of literature and selected documents. It begins with a discussion concerning the main doctrinal branches presented (Functionalist, Normative and Pluralist Schools). Based on the insights of critical International Law historiography, it examines the conditions of the production of a historical discourse that is apt to conciliate contrasting, ambivalent and contextualized perceptions of global legal relations. In sequence, stirred by the works of the Third World Approaches to International Law movement (TWAIL), it sheds light over the relevance of an ongoing examination of colonial and imperial processes that is capable of surpassing traditional readings of the theme. It argues that other forms of social organization or constitutional designs might as well have been eclipsed or lack conventional legitimacy over the past centuries. This paper concludes by enforcing a continuous critical engagement with history, colonialism and imperialism, and an open dialogue with less evident constitutional designs.
\end{abstract}

Keywords: Global Constitutionalism; Legal History; International Legal Theory 


\section{SUMÁRIO}

INTRODUÇAO; 1 O CONSTITUCIONALISMO ALÉM DO ESTADO; 2 UM BREVE EXAME DO CONSTITUCIONALISMO GLOBAL: ABORDAGENS FUNCIONALISTA, NORMATIVA E PLURALISTA; 2.1 A Escola Funcionalista; 2.2 A Escola Normativa; 2.3 A Escola Pluralista; 3 HISTORIOGRAFIA CRÍTICA, CONSTITUCIONALISMO GLOBAL E EMANCIPAÇÃO; CONCLUSÃO; REFERÊNCIAS.

\section{INTRODUÇÃO}

Desde o começo da década de 1990, a ideia de constitucionalização do Direito Internacional vem ganhando proeminência nos fóruns de debates e na agenda dos internacionalistas. No núcleo das discussões está a questão da necessidade de regulação das relações internacionais em meio a um processo de aumento de centros de autoridade situados além dos Estados, que evocam participação nas questões globais, mas que, em contrapartida, pode não vir acompanhada da atribuição de responsabilidade final por seus atos - accountability.

A carência de uma autoridade centralizada e capaz de impor a força da lei, atributo típico da sociedade internacional, permite que variados centros de poder disputem a legitimidade no trato das questões mais urgentes, como os Direitos Humanos, o comércio ou a proteção ambiental, e, ao desempenharem papéis antes reivindicados com exclusividade pelos entes estatais, trazem consigo novos questionamentos, dentre os quais destacamos, sem prejuízo dos demais, a relevância normativa do Direito Internacional, o risco de fragmentação do sistema jurídico, o papel das organizações internacionais, os limites dos poderes dos órgãos executivos (por exemplo, as smart sanctions do Conselho de Segurança), ou a participação de entes não-estatais na governança global.

Em meio a esta variedade temática, há de se ater à problematização relativa ao aprofundamento histórico relativos aos pressupostos teóricos contemplados pelo Constitucionalismo Global. Para tanto, a riqueza analítica dos postulados historiográficos do Direito Internacional será transplantada para as discussões centrais do Constitucionalismo Global, almejando-se, por esta via, um apanhado crítico dos rumos esperados pela constitucionalização em vista das contrastantes demandas globais por emancipação, reconhecimento e diversidade. 
O objetivo do trabalho é trazer a lume algumas contribuições da teoria crítica do Direito Internacional para todo o projeto do constitucionalismo global. O estudo da história da disciplina, antes rotulado como uma tarefa metódica e rotineira, cada vez mais confere ao internacionalista uma responsabilidade que não pode ser descartada. Não é sem razão que pensadores como Martti Koskenniemi ${ }^{1}$, Antony Anghie $^{2}$ e David Kennedy ${ }^{3}$ destacam o ressurgimento dos estudos históricos do Direito Internacional.

A variedade de abordagens que o tema desperta autoriza que se organizem as diferentes propostas em pelo menos três grandes Escolas de pensamento. ${ }^{4}$ A Escola Funcionalista espera mapear as instituições com a finalidade de identificar aquelas que já desempenham ou que possam vir a desempenhar alguma função tipicamente constitucional. A denominada Escola Normativa emprega esforço diverso: propor um rol de normas que irão moldar a sociedade global, conjunto este de normas geralmente espelhado nas experiências constitucionais domésticas. A Escola Pluralista, terceiro grupo, conjuga uma combinação de iniciativas que mapeiam as múltiplas experiências constitucionais, não confinadas aos seus referenciais domésticos ou supranacionais, e propostas de arranjos institucionais contingentes e historicamente situados. A primeira parte deste trabalho (seções 1 e 2) é destinada à apresentação dos postulados centrais de cada uma destas escolas.

O que torna os debates contemporâneos envolvendo a constitucionalização do Direito Internacional particularmente relevantes é a sua abertura a diferentes propostas, originadas de variadas fontes políticas e jurídicas. No cerne da análise da Escola Pluralista, dois eixos de apreciação se sobressaem: de um lado, os desafios propostos pela historiografia crítica jusinternacionalista e, de outro, o resgate das dinâmicas coloniais e imperiais em seu cotejo na consolidação do discurso legalista no começo do Século XXI. A segunda parte deste trabalho (seção 3) é destinada ao desenvolvimento destes dois temas, em particular sua contribuição para o pensamento constitucionalista em nível global.

\footnotetext{
1 KOSKENNIEMI, Martti. Histories of International Law: Dealing with Eurocentrism. Rechtsgeschichte, Frankfurt am Main, vol. 19, p. 152-176, 2011; KOSKENNIEMI, Martti. The Gentle Civilizer of Nations. The Rise and Fall of International Law 1870-1960. Cambridge: Cambridge University Press, 2001.

${ }^{2}$ ANGHIE, Antony. Imperialism, Sovereignty and the Making of International Law. Cambridge: Cambridge University Press, 2004.

${ }^{3}$ KENNEDY, David. The Disciplines of International Law and Policy. Leiden Journal of International Law, Leiden, v. 12, n. 1, p. 9-133, 1999.

4 WIENER, Antje. Global Constitutionalism. Oxford Bibliographies Online, 2012. Disponível em: <http://www.oxfordbibliographies.com/view/document/obo-9780199743292/obo-9780199743292-

0092.xml>. Acesso em: 31 de ago.de 2014; WIENER, Antje; LANG, Anthony F.; TULLY, James; MADURO, Miguel Poiares; KUMM, Mattias. Global Constitutionalism: Human rights, democracy and the rule of law. Global Constitutionalism, Hamburg, vol. 1, no.1, p. 1-15, 2012.
} 
A forma como concebemos a história repercute na nossa visão do presente, e lança luz sobre o que é imprescindível ou o que é dispensável; de outro modo, relega ao esquecimento eventos, práticas e processos que podem permitir uma melhor compreensão das vozes, estórias ou "não-eventos" que lutam por reconhecimento. Em sintonia com estes estudos, a percepção de possíveis persistentes elementos imperiais e coloniais no bojo da teoria constitucional (e internacional) contemporânea ilustra o grau de abertura dialógica vis-à-vis a produção de uma teoria constitucional plural, diversa, cultural e temporalmente contingente.

\section{O CONSTITUCIONALISMO ALÉM DO ESTADO}

O constitucionalismo moderno, seja em sua vertente nacional, seja em arranjos supra ou internacionais, alicerça sua legitimidade em dois imperativos igualmente fundamentais, porém antagônicos. 0 primeiro é a ideia de que o poder governamental - ou estatal - é gerado pelo consentimento do povo. O segundo consiste na máxima de que, para ser efetivo e sustentado, tal poder deve ser dividido, exercido e restringido por distintas formas institucionais. Martin Loughlin e Neil Walker explicam a relevância desta tensão essencial, ou paradoxal, que exprime a oposição clássica entre democracia e legalismo: “o poder que eles [0 povo] possuem, assim pode parecer, só pode ser exercido pelas formas constitucionais já estabelecidas ou no processo de serem estabelecidas. Isto indica o que, em sua formulação mais elementar, poderia ser chamado de paradoxo do constitucionalismo." 5

A conciliação do paradoxo em questão em princípio requer análises que não se limitam nas fronteiras do Estado. Assim, os citados autores apontam certas tendências globais aptas a conferir ao constitucionalismo moderno novas (ou antigas) versões e significados. Assim sendo, o discurso triunfalista da democracia liberal, as rivalidades étnicas confinadas no espaço geográfico estatal, as múltiplas identidades com suas variadas políticas de autoafirmação cultural, a emergência de redes transnacionais de governança, são todos temas de repercussão contemporânea a desafiar os arranjos institucionais oriundos da modernidade.

A identificação do corpo político com as formas constitucionais em que se insere, e sobre as quais exerce a expectativa de permanente reconciliação desta identidade, traz à tona

5 LOUGHLIN, Martin; WALKER, Neil. Introduction. (eds.). The Paradox of Constitutionalism: Constituent Power and Constitutional Form. Oxford: Oxford University Press, 2007, p. 1. Tradução livre: "The power they possess, it would appear, can only be exercised through constitutional forms already established or in the process of being established. This indicates what, in its most elementary formulation, might be called the paradox of constitutionalism." 
questão da necessidade de afirmação de estruturas constitucionais provisionais, não resistentes às demandas sociais. Mas esta premissa está condicionada à forma como se caracteriza o papel do povo: ou se admite a concepção hobbesiana de povo enquanto multitude passiva, ou se admite a radical expressão do povo como agente de mudança.

Os debates contemporâneos acerca do constitucionalismo global, também referido como a constitucionalização global, incidem diretamente nas estruturas do Direito Internacional. Ao discutir este fenômeno, especialistas em direito e em ciência política devem considerar a questão essencial levantada por Loughlin e Walker, também referida por Antje Wiener: as raízes da legitimidade do poder estatal repousam na concepção de que os membros de uma comunidade política, personificando o poder constituinte, estabelecem um acordo comum sobre a criação das que irão regular sua comunidade. ${ }^{6}$ A dinâmica produzida da interação entre poder constituído e poder constituinte repercute não apenas na aferição da legitimidade das regras e do poder em nível estatal, como também tem se mostrado, desde já, elemento crucial para os contornos teóricos e práticos do constitucionalismo global.

Certa confusão revolve os conceitos de constitucionalismo global e governança global. Ainda que ambos tratem da relação entre ordem e poder no plano internacional, é imperativo constatar que possuem delimitações claras. A atividade do constitucionalismo global reflete uma guinada nas relações internacionais: de relações globalizadas tipicamente desreguladas para um aprimoramento institucional e referência normativa difusa, compondo um cenário de "constitucionalismo livre". ${ }^{7}$ Os postulantes da governança global, cujo marco temporal é simbolicamente situado no final da Guerra Fria, acenam para uma nova Era onde a autoridade estatal sofre deslocamento contínuo, tanto internamente quanto sob a influência de entidades supranacionais. Em consequência, o exercício das atividades que viabilizam a vida humana governança - podem ser derivados ou não de fontes legais prescritas, e realizados ou não por órgãos governamentais. Em suma, a governança global equaciona as mudanças advindas da globalização e almeja compor um plano de trabalho onde se confere menos relevância à fonte da autoridade do que à sua eficácia.

\footnotetext{
6 LOUGHLIN, Martin; WALKER, Neil. Introduction. (eds.). The Paradox of Constitutionalism: Constituent Power and Constitutional Form. Oxford: Oxford University Press, 2007, p. 6; WIENER, Antje. Global Constitutionalism. Oxford Bibliographies Online, 2012. Disponível em: <http://www.oxfordbibliographies.com/view/document/obo-9780199743292/obo-97801997432920092.xml>. Acesso em: 31 ago. 2014.

7 WIENER, Antje; LANG, Anthony F.; TULLY, James; MADURO, Miguel Poiares; KUMM, Mattias. Global Constitutionalism: Human rights, democracy and the rule of law. Global Constitutionalism, Frankfurt am Main, vol. 1, no.1, 2012, p. 8. Tradução livre: "free constitutionalism".
} 
Contudo, o reexame da tensão entre poder governamental e poder constituinte, que também é externada pelas dicotomias democracia versus legalismo e transformação versus estabilidade, pode colocar em cheque a fundação contratualista das modernas constituições. Por outro lado, as constituições geralmente conectam suas origens a algum momento edificante da comunidade política que trará definições sobre como direcionar a tensão em tela. Enquanto a defesa da tese do povo como abstração pode resultar na resolução da tensão em favor das formas constitucionais, o urgente reconhecimento de tal momento edificante pode carregar um teor retórico capaz de legitimar a exploração de minorias e a manter intactas profundas desigualdades sociais. O povo, neste último caso, nada mais é que um artifício de manobra, sobre o qual advertem Loughlin e Walker: "a autoridade constituída (os executores do poder) simplesmente usa o discurso do constitucionalismo como um meio para promover sua regra". ${ }^{8}$

Uma forma válida de se examinar o paradoxo constitucional consiste em tratar o constitucionalismo não apenas como uma ferramenta a serviço de formas hegemônicas - muitas vezes ocultas - de poder nas sociedades modernas em vários níveis, mas também, e especialmente, como o ponto de partida para releituras contra-hegemônicas do papel da constituição e sua relação com a democracia.

As experiências constitucionais, em variados níveis - não somente nacional ou global, mas também subnacional, regional, etc -, podem não apresentar os contornos clássicos propostos pela tradição constitucional moderna. O enfoque constitucionalista, consoante a indispensável reflexão de James Tully ${ }^{9}$, deve sempre trazer consigo significados contextualizados, o que evidencia o inerente caráter contingencial do constitucionalismo. Sendo uma atividade pautada pela contingência e, portanto, localizada em contextos culturais e históricos específicos, únicos em suas particularidades, tem-se que a insistência na adoção de um modelo único e universal, ou seja, a adoção de standards constitucionais universais, consoante advoga parcela das propostas do constitucionalismo global, carrega o risco de descredenciar, deslegitimar ou ocultar práticas constitucionais contextualmente situadas.

8 LOUGHLIN, Martin; WALKER, Neil. Introduction. (eds.). The Paradox of Constitutionalism: Constituent Power and Constitutional Form. Oxford: Oxford University Press, 2007, p. 3. Tradução livre: "The constituted authority (the power-wielders) simply use the discourse of constitutionalism as a means of promoting their rule."

9 TULLY, James. Modern Constitutional Democracy and Imperialism. Osgoode Hall Law Journal, York, vol. 46, p. 461-493, 2008; TULLY, James. Strange Multiplicity. Constitutionalism in an Age of Diversity. Cambridge: Cambridge University Press, 1995. 


\section{UM BREVE EXAME DO CONSTITUCIONALISMO GLOBAL: ABORDAGENS FUNCIONALISTA, NORMATIVA E PLURALISTA}

Os debates doutrinários em torno do constitucionalismo global podem ser caracterizados, a um só tempo, como heterogêneos e interdisciplinares. São heterogêneos porque estruturam suas teses sobre diferentes e contrastantes pressupostos. $E$ são interdisciplinares na medida em que não limitam suas análises a parâmetros estritamente legalistas. Deste modo, em recente apanhado bibliográfico sobre o tema, Antje Wiener e outros identificam, de um lado, três escolas com propostas bem distintas e, de outro lado, algumas propostas interdisciplinares, em geral abrangendo perspectivas históricas, sociológicas e filosóficas. $^{10}$

A primeira escola é apresentada pela designação funcionalismo, e reponde pelos estudos dos processos de constitucionalização que são revelados por meio de barganhas e negociações nos ambientes institucionais. A tarefa central desta escola é mapear o terreno global à procura de procedimentos e acordos que regulam estruturalmente as relações internacionais contemporâneas, identificando institutos capazes de desempenhar funções tipicamente constitucionais: controle e divisão do poder em nível global, controle jurisdicional de atos normativos, proteção a um hall de direitos humanos fundamentais, em particular. Esta abordagem tem sua melhor exposição no trabalho de Dunoff e Trachtman. ${ }^{11}$

Diferente exploração é conduzida pela escola normativa. O conjunto de doutrinadores que compõe este grupo antevê no constitucionalismo global um movimento estratégico para o estabelecimento de uma constituição global ou, na impossibilidade desta, o fortalecimento do constitucionalismo global para que esteja apto a fornecer, de forma compensatória ${ }^{12}$, determinado conteúdo normativo que tenha sido esvaziado em nível estatal em decorrências das forças da governança global e da globalização. A ênfase recai sobre o progressivo

\footnotetext{
10 WIENER, Antje. Global Constitutionalism. Oxford Bibliographies Online, 2012. Disponível em: <http://www.oxfordbibliographies.com/view/document/obo-9780199743292/obo-9780199743292-

0092.xml>. Acesso em: 31 ago. 2014; WIENER, Antje; LANG, Anthony F.; TULLY, James; MADURO, Miguel Poiares; KUMM, Mattias. Global Constitutionalism: Human rights, democracy and the rule of law. Global Constitutionalism, Hamburg, vol. 1, no.1, 2012, p. 1-15.

${ }_{11}$ DUNOFF, Jeffrey L.; TRACHTMAN, Joel P. A Functional Approach to International Constitutionalization. In: _ (eds.) Ruling the World? Constitutionalism, International Law, and Global Governance. Cambridge: Cambridge University Press, 2009, p. 3-36.

12 PETERS, Anne. The Merits of Global Constitutionalism. Indiana Journal of Global Legal Studies, Bloomington, vol. 16, no. 2, 2009, p. 397-411; PETERS, Anne. Compensatory Constitutionalism: The Function and Potential of Fundamental International Norms and Structures. Leiden Journal of International Law, Leiden, vol. 19, no. 3, 2006, p. 579-610.
} 
desenvolvimento ou reforma política e legal de práticas além da esfera de influência dos Estados, sugerindo um comprometimento com standards constitucionais. As dinâmicas peculiares do constitucionalismo derivado do Direito Comunitário Europeu, o fortalecimento das normativas comercias empregadas em sede da Organização Mundial do Comércio e a defesa da Carta das Nações Unidas como o melhor esboço de uma constituição para a sociedade internacional, compreendem três dos eixos de pesquisa que mais ganharam evidência na última década. ${ }^{13}$

0 teor universalista presente nas duas primeiras escolas é rebatido pela escola pluralista. Esta escola procura teorizar o constitucionalismo enquanto fenômeno contextualizado, contingente e constitutivo. A vocação crítica desta corrente lança luz para a tendência de se aplicar ideais regulativos neokantianos - sob as formas do federalismo e do liberalismo cosmopolita - para o estabelecimento dos alicerces regulatórios do constitucionalismo global. A escola combina uma análise reflexiva típica do mapeamento dos processos sociais com uma atividade de natureza construtiva. Escreve Wiener a respeito da vocação dos pluralistas:

A escola leva em consideração as práticas sociais do constitucionalismo na medida em que elas se estendem para além dos limites do estado moderno, com a intenção de identificar uma variedade de possíveis e desejáveis princípios, normas, e regras do constitucionalismo que são consideradas apropriadas por uma pluralidade de atores globais. ${ }^{14}$

Dentre as propostas interdisciplinares, podemos constatar eixos de pesquisa que exploram a intersecção de duas escolas de pensamento, integrando ainda métodos de análise típicos das ciências sociais, e em especial das relações internacionais. 0 fator interdisciplinaridade vem à tona de forma mais evidente nestas abordagens, deixando transparecer ainda a escassa delimitação das fronteiras entre as escolas.

\footnotetext{
${ }^{13}$ FASSBENDER, Bardo. Rediscovering a Forgotten Constitution: Notes on the Place of the UN Charter in the International Legal Order. In: DUNOFF, Jeffrey L.; TRACHTMAN, Joel P. (eds.). Ruling the World? Constitutionalism, International Law, and Global Governance. Cambridge: Cambridge University Press, 2009, p. 133-147.

14 WIENER, Antje. Global Constitutionalism. Oxford Bibliographies Online, 2012. Disponível em: <http://www.oxfordbibliographies.com/view/document/obo-9780199743292/obo-9780199743292-

0092.xml>. Acesso em: 31 ago de 2014. Tradução livre: "The school takes into account the social practices of constitutionalism as they extend beyond modern state boundaries with the intention of identifying the variety of possible and desired principles, norms and rules of constitutionalism that are considered appropriate by a plurality of global actors."
} 


\subsection{A Escola Funcionalista}

Jeffrey Dunoff e Joel Trachtman empregam metodologia funcionalista a fim de compreender as três tarefas essenciais desempenhadas pelo constitucionalismo global. ${ }^{15} \mathrm{~A}$ primeira função consiste na identificação de normas que favorecem a produção do Direito Internacional ordinário. Nesta categoria se enquadram a Carta das Nações Unidas, que confere ao Conselho de Segurança o poder de criar normas vinculantes aos Estados, e a Corte Europeia de Justiça - de alcance regional -, cujas decisões ajudam a firmar a autoridade de atores nacionais e supranacionais. Esta primeira função tem por objetivo permitir a alocação de autoridade. A segunda função é exercida por normas constitucionais que restringem a produção do Direito Internacional ordinário.

Nestes termos, soberania e jus cogens seriam categorias de normas cuja atuação impede a produção de normas que possam comprometê-las. Por exemplo, enquanto o artigo 24(1) da Carta da ONU atribui certos poderes ao Conselho de Segurança, o artigo 24(2) restringe sua atuação, vinculando o exercício de poder deste órgão à realização dos objetivos e princípios da Carta. ${ }^{16}$ Por fim, a terceira categoria de normas constitucionais opera mediante suplementação das normas nacionais, suprindo deficiências domésticas ou redefinindo o escopo de aplicação de normas de variados níveis. Estas normas atuam quando algum atrito entre as esferas domésticas, supranacional e internacional der origem a dúvidas quanto à extensão da efetividade de provimentos internacionais em face dos demais sistemas jurídicos. Em conjunto, as três funções mediam e reconciliam as demandas oriundas da sociedade internacional e a regulamentação destas pelo direito:

Entendemos as constituições legais como esforços para efetuar ou instanciar as estruturas sociais escolhidas. De outro modo, podemos entender a seleção de aspectos específicos de uma constituição, tanto inicialmente quanto

\footnotetext{
${ }^{15}$ Segundo esclarecem os autores, a metodologia funcional possui o mérito de permitir o exame das funções desempenhadas por determinado instituto ou conjunto de regras, e evitar as armadilhas que se formam em torno das análises que buscam propor conceitos fechados, isto é, definir o que é e o que não é uma norma constitucional. Cf. DUNOFF, Jeffrey L.; TRACHTMAN, Joel P. A Functional Approach to International Constitutionalization. In: _ (eds.) Ruling the World? Constitutionalism, International Law, and Global Governance. Cambridge: Cambridge University Press, 2009, p. 9-10.

${ }^{16}$ Artigo 24 - 1. A fim de assegurar pronta e eficaz ação por parte das Nações Unidas, seus Membros conferem ao Conselho de Segurança a principal responsabilidade na manutenção da paz e da segurança internacionais e concordam em que no cumprimento dos deveres impostos por essa responsabilidade o Conselho de Segurança aja em nome deles. 2. No cumprimento desses deveres, o Conselho de Segurança agirá de acordo com os Propósitos e Princípios das Nações Unidas.
} 
dinamicamente, como uma oportunidade para (re)negociar, implicitamente ou explicitamente, estruturas sociais fundamentais. ${ }^{17}$

Um conjunto de mecanismos constitucionais, na expressão de Dunoff e Trachtman, entra em ação a fim de executar as funções do constitucionalismo global. Mecanismos de governança podem atuar em nível horizontal, devidamente dotados de parcela de poder decorrente da divisão ou separação de funções e competências no contexto internacional. Em nível vertical, mecanismos de governança funcionam estabelecendo diretrizes e procedimentos. Em adição, a constitucionalização em nível global pode contribuir para o estabelecimento de regras hierarquicamente superiores, amparadas em uma visão monista com prevalência do Direito Internacional.

Estes primeiros mecanismos coexistem com outros importantes marcos constitucionais. A estabilidade das normas constitucionais difere de arranjos de soft law por oferecem certa resistência às pressões contingenciais e se assemelham a regras produzidas pela via convencional. Ademais, a tradição constitucional funda sua legitimidade na garantia de direitos fundamentais, os quais existem em nível global. Fundada na ideia de supremacia, a garantia de sistemas de revisão constitucional, ou de controle de atos normativos em face do corpo constitucional, asseguraria melhores patamares para acordos políticos e harmonização de interesses. Finalmente, a tarefa constitucional não apenas cria condições para o exercício democrático como também é objeto de atuação deste mesmo exercício, limitando poderes, fixando novas metas, ou reinventando os moldes de legitimação democrática.

De contornos funcionalistas, muita atenção tem sido dada à ideia de fragmentação do Direito Internacional. Em síntese, levanta-se a tese de que o crescimento descoordenado e independente dos chamados regimes internacionais subsistêmicos possa colocar em cheque as tentativas de sistematização do Direito Internacional como um todo. 0 desenvolvimento autossuficiente dos regimes - direitos humanos, comércio, meio ambiente, direito penal, por exemplo - poderia comprometer a consistência e a abrangência da disciplina, uma vez que cada regime seguiria uma lógica institucional própria, adaptada às demandas particulares de cada tema tratado. Em decorrência da coexistência de racionalidades institucionais díspares, decisões

\footnotetext{
17 DUNOFF, Jeffrey L.; TRACHTMAN, Joel P. A Functional Approach to International Constitutionalization. In: _ (eds.) Ruling the World? Constitutionalism, International Law, and Global Governance. Cambridge: Cambridge University Press, 2009, p. 18. Tradução livre: "We understand legal constitutions as efforts to effectuate or instantiate the selection of the specific features of a constitution, both initially and dynamically, as an opportunity to (re)negotiate, implicitly or explicitly, fundamental social structures."
} 
contraditórias de órgãos jurisdicionais globais ou regionais poderiam afetar negativamente a coerência normativa geral do direito internacional. ${ }^{18}$

A fragmentação traz à tona questionamentos sobre a relevância das normas gerais de Direito Internacional em um contexto de diferenciação sistêmica e especialização funcional, quando os subsistemas ora parecem se afastar do regramento geral, ora não hesitam em reafirmar a natureza residual do Direito Internacional geral. A solução que o constitucionalismo global poderia trazer para este cenário se desdobra em duas vias: a primeira trabalha com a promoção de hierarquia e ordem por meio de mecanismos capazes de gerenciar ou resolver eventuais conflitos, conferindo maior previsibilidade às relações internacionais, e a segunda, um esforço de coordenação de racionalidades específicas, em oposição à produção de hierarquias a partir da centralização do poder global.

As dinâmicas sociais e históricas, de um lado, e os arranjos de poder, de outro, conferem a esta estrutura funcionalista diferentes usos e configurações. 0 paradoxo constitucional estudado por Loughlin e Walker ${ }^{19}$ reflete a tensão entre estabilidade e mudança que a abordagem funcionalista discute e elege como componente nuclear da matéria constitucional. Se adotarmos como ponto de partida a experiência doméstica, o paradoxo constitucional em nível internacional apresentará questões ainda mais complexas, além de indefinições teóricas que devem ser escrutinadas.

\subsection{A Escola Normativa}

O internacionalista Andreas Paulus levanta argumentos contrários às premissas adotadas pelo funcionalismo, e ilustra sua crítica com exemplos de limitações das supostas funções constitucionais do sistema institucional da ONU. O Art. 103 da Carta, neste sentido, não almeja maior aplicação do que nas ocasiões de conflitos de normas, assim como o Art. 38 do Estatuto da CIJ, rol de fontes clássicas da matéria, não está integrado à Carta. Contudo, parece que sua crítica repousa de modo mais incisivo na constatação de que a Carta da ONU não está voltada para a aplicação de sanção frente ao desrespeito do Direito Internacional, mas está dedicada à manutenção da paz e da segurança. Todavia, nem este última constatação está isenta de

\footnotetext{
${ }^{18}$ FISCHER-LESCANO, Andreas; TEUBNER, Gunther. Regime Collisions: the vain search for legal unity in the fragmentation of global law. Michigan Journal of International Law, Michigan, vol. 25, no. 4, 2004, p. 999-1046.

19 LOUGHLIN, Martin; WALKER, Neil. Introduction. In: (eds.). The Paradox of Constitutionalism: Constituent Power and Constitutional Form. Oxford: Oxford University Press, 2007, p. 1-7.
} 
apreciação cética, haja vista o histórico de abusos de membros permanentes do Conselho de Segurança. Se considerarmos que os argumentos contrários à supremacia constitucional da Carta da ONU e de seus órgãos são suficientemente fortes e convincente, abrimos o caminho para a visão fragmentária do direito internacional. Por esta via conclui Paulus:

A defesa do constitucionalismo internacional é duvidosa não apenas se comparada aos modelos domésticos - que também podem ser menos perfeitos e abrangentes que o sugerido pelo modelo ideal - mas também com respeito ao seu reconhecimento pelos sujeitos de direito. Elemento adicional do constitucionalismo formal, a ideia de que um sistema legal internacional completo se deriva de uma fonte particular e concreta traz à tona o espectro da fragmentação, e não o da constitucionalização. ${ }^{20}$

Determinadas propostas de constitucionalização do Direito Internacional defendem a identificação de normas substanciais, em geral princípios, que estruturam a ordem normativa global ao ponto de comporem um núcleo material universal. As normas de jus cogens, cujo catálogo típico inclui a proibição do uso da força e do genocídio, direitos humanos básicos, e o direito à auto-determinação, integram o referido núcleo, mas não podem ser considerados elementos suficientes e necessários ao constitucionalismo global. Assim, se existem dúvidas razoáveis acerca da universalidade do conteúdo das normas cogentes, o caminho mais promissor para a composição do constitucionalismo global seria, em primeira análise, a identificação, em nível internacional, de equivalentes para certos elementos do constitucionalismo nacional. Um exercício analógico desta natureza teria o benefício de apontar tanto para aspectos de proximidade entre as duas perspectivas quanto para temas sobre os quais dificilmente poder-seia advogar de forma plausível, em defesa de um standard mínimo de equivalência.

O fortalecimento do constitucionalismo global traria consigo mais amplo controle sobre a legitimidade do Direito Internacional. Em resposta para a crítica que atribui ao constitucionalismo em nível global um papel, de um lado, ora central na legalização das relações de poder, e de outro, ora por demais idealista e afastado dos problemas reais da sociedade internacional, certos autores evitam se posicionar em algum destes extremos, focando a análise

\footnotetext{
20 PAULUS, Andreas L. The International Legal System as a Constitution. In: DUNOFF, Jeffrey L.; TRACHTMAN, Joel P (eds.). Ruling the World? Constitutionalism, International Law, and Global Governance. Cambridge: Cambridge University Press, 2009, p.81. Tradução livre: "The case for an international constitutionalism is doubtful not only compared to the domestic models - which may also be less perfect and comprehensive than the ideal model would suggest - but also with regard to its recognition by the subjects of the law. A further element of a formal constitutionalism, the idea of a complete derivation of the international legal system from one particular and concrete source, raises the specter of fragmentation rather than constitutionalization."
} 
nos usos e abusos e ao afastamento das necessidades quotidianas que podem resultar. Nesse sentido é o posicionamento de Anne Peters, para quem “[...] o constitucionalismo global, enquanto agenda acadêmica, deveria seguir o caminho do meio entre um mero dignificar do status quo e um ancorar em sonhos acadêmicos."21

Peters sugere pensar o constitucionalismo menos em termos de suas funções e mais em seu potencial normativo e prescritivo, esforço que conduziria a análises mais substanciais das carências do sistema jurídico internacional. Quando se tem em mente a projeção do constitucionalismo para além do Estado, é imprescindível que tal projeção não se limite às formas constitucionais estatais, cujos contornos são bem sedimentados na tradição jurídica ocidental. Em consequência, pensar o constitucionalismo globalmente em termos materiais repercutirá em melhor controle sobre a legitimidade das normas internacionais, além de interferir positivamente na constitucionalização de pontos frágeis em nível estatal. Dito de outra maneira, o constitucionalismo global se relacionaria subsidiariamente com as constituições nacionais:

Em uma perspectiva constitucionalista, a valoração das normas em jogo deve ser conduzida de maneira mais sutil, de acordo com seu peso e importância substantivos. Tal perspectiva, não-formalista e orientada pela substância, sugere que provisões de constituições estatais de menor significância teriam que ceder espaço para importantes normas internacionais. ${ }^{22}$

0 mais forte elo entre as constituições nacionais e a constituição internacional é a proteção do ser humano, assim postulam Anne-Marie Slaughter e William Burke-White ${ }^{23}$ em aproximação da posição de Peters. 0 mundo pós 11 de Setembro de 2001 experimenta um "novo momento constitucional internacional” no qual a máxima da inviolabilidade civil veio, de forma gradual, porém resoluta, a eleger a proteção do ser humano na condição de norma estruturante de todas as normas de jus bellum. O panorama de conflitos internacionais que se estabeleceu

${ }^{21}$ PETERS, Anne. The Merits of Global Constitutionalism. Indiana Journal of Global Legal Studies, Bloomington, vol. 16, no. 2, 2009, p. 402. Tradução livre: "Global constitutionalism as an academic agenda should follow the middle path between merely dignifying the status quo and hanging onto academic pipe dreams."

${ }^{22}$ PETERS, Anne. The Merits of Global Constitutionalism. In: Indiana Journal of Global Legal Studies, Bloomington, vol. 16, no. 2, 2009, p. 406. Tradução livre: “In a constitutionalist perspective, the ranking of the norms at stake must be assessed in a more subtle manner, according to their substantive weight and significance. Such a non-formalist, substance-oriented perspective suggests that provisions in state constitutions with minor significance would have to give way to important international norms."

${ }^{23}$ SLAUGHTER, Anne-Marie; BURKE-WHITE, William. An International Constitutional Moment. Harvard International Law Journal, Cambridge, vol. 43, no. 1, 2002, p. 1-21. 
nas últimas décadas significou que os Estados guerreiam menos entre si, e que estes mesmos representam, em diversas ocasiões, a maior ameaça à paz e aos seus próprios cidadãos. As guerras étnicas, civis, os movimentos de secessão, além das ações voltadas para o extermínio total ou parcial da própria população e do terrorismo, realizam-se dentro da proteção da clássica concepção de soberania estatal, desafiando os limites legais às ações da comunidade internacional.

Em análise, o artigo 2(4) da Carta da $\mathrm{ONU}^{24}$, no entender dos referidos autores, não lograria mais êxito na tarefa de impedir o uso da força armada em um mundo radicalmente transformado, no qual o inimigo transcende os limites estatais e atua sob a forma de redes multiconectadas e independentes, de alcance e influência global. Por isso, ao invés de se falar em guerras, ao se focar em 'ações armadas' [...] reconhece-se as muitas maneiras pelas quais conflitos armados organizados podem ameaçar a paz e a segurança internacional, independentemente da identidade dos ofensores ou o alcance territorial de sua causa". ${ }^{25}$

Em vista deste novo cenário, a ênfase da constitucionalização do Direito Internacional deve ser canalizada para o reconhecimento do princípio da inviolabilidade civil. Diversos diplomas legais internacionais, como as Convenções de Genebra de 1949 - cuja proteção do indivíduo em situações diversas daquelas consideradas conflitos internacionais vem prevista no artigo 3, comum às quatro Convenções ${ }^{26}$-, e a experiência dos Tribunais criminais ad hoc ${ }^{27}$ desde

\footnotetext{
${ }^{24}$ Carta da ONU, Artigo $2^{\circ}$ - A Organização e seus Membros, para a realização dos propósitos mencionados no Artigo 1, agirão de acordo com os seguintes Princípios:

4. Todos os Membros deverão evitar em suas relações internacionais a ameaça ou o uso da força contra a integridade territorial ou a dependência política de qualquer Estado, ou qualquer outra ação incompatível com os Propósitos das Nações Unidas.

${ }^{25}$ SLAUGHTER, Anne-Marie; BURKE-WHITE, William. An International Constitutional Moment. In: Harvard International Law Journal, vol. 43, no. 1, 2002, p. 5. Tradução livre: “Focusing on 'armed conflict' [...] recognizes the many ways in which organized armed violence can threaten international peace and security, regardless of the identity of specific attackers or the territorial scope of their struggle."

${ }^{26}$ A referência às Convenções de Genebra de 1949 converge para o artigo 3, que provê as disposições a serem aplicadas em ocasião de conflito armado que não se enquadrem na definição estipulada pela Carta da ONU:

Artigo 3. No caso de conflito armado que não apresente um caráter internacional e que ocorra no território de uma das Altas Partes contratantes, cada uma das Partes no conflito será obrigada aplicar, pelo menos, as seguintes disposições:

1) As pessoas que não tomem parte diretamente nas hostilidades, incluindo os membros das forças armadas que tenham deposto as armas e as pessoas que tenham sido postas fora de combate por doença, ferimentos, detenção, ou por qualquer outra causa, serão, em todas as circunstâncias, tratadas com humanidade, sem nenhuma distinção de caráter desfavorável baseada na raça, cor, religião ou crença, sexo, nascimento ou fortuna, ou qualquer outro critério análogo.

Para este efeito, são e manter-se-ão proibidas, em qualquer ocasião e lugar, relativamente às pessoas acima mencionadas:
} 
1990, contribuíram para o estreitamento dos esforços para a criação de uma jurisdição penal permanente, de atuação complementar à jurisdição estatal. Em suma, a grande relevância da legislação internacional de Direitos Humanos e de Direito Humanitário, dos arranjos ad hoc e da jurisdição permanente do Tribunal Penal Internacional remete à tendência de individualização do Direito Internacional.

A consolidação deste processo traria melhores perspectivas para o endereçamento de uma urgente questão: o terrorismo. Em face das dificuldades em se alcançar um consenso sobre a definição de terrorismo ${ }^{28}$, uma alternativa abordagem sugerida é redirecionar a análise para aqueles que foram ou são vítimas em potencial. À luz do novo momento constitucional sugerido por Slaughter e Burke-White, a aplicação do princípio da inviolabilidade civil permitiria central a atenção na proteção destes últimos, e com isso evitar-se-iam os inconvenientes da delimitação de um conceito para o terrorismo. Os autores defendem esta conclusão quando insistem que “[...] o ponto fundamental em risco não é o desejo de disseminar o terror, mas sim os tipos de alvos visados. Os civis não devem ser alvos de ataques deliberados, em nenhuma circunstância, por nenhum propósito."29

a) As ofensas contra a vida e a integridade física, especialmente o homicídio sob todas as formas, mutilações, tratamentos cruéis, torturas e suplícios;

b) A tomada de reféns;

c) As ofensas à dignidade das pessoas, especialmente os tratamentos humilhantes e degradantes;

d) As condenações proferidas e as execuções efetuadas sem prévio julgamento, realizado por um tribunal regularmente constituído, que ofereça todas as garantias judiciais reconhecidas como indispensáveis pelos povos civilizados.

$[\ldots]$

${ }^{27}$ No julgamento do caso Prosecutor v. Martić, o Tribunal Penal Internacional para a Ex-lugoslávia (1996, parágrafo $8^{\circ}$ ), considerou que "[...] the rule that the civilian population as such as well individual citizens shall not be the object of attack is a fundamental rule of international law applicable to all armed conflicts [...] irrespective of their characterization as international or non-international". TRIBUNAL PENAL INTERNACIONAL PARA A EX-IUGOSLÁVIA (TPII). Prosecutor v. Martić, Case No. IT-95-11, Decisão de 8 de março de 1996. Disponível em: <http://www.icty.org/case/martic/4>. Acesso em: 25 ago de 2014.

${ }^{28}$ A carência de uma definição que possa seguramente orientar a prevenção e repressão ao terrorismo fazem do termo objeto de retórica, desprovido de poder analítico. Explicam Slaughter e Burke-White: "Traditionally, international treaties or national criminal statutes regulating terrorism have focused on preventing the spread of terror. This focus is rhetorically expedient but analytically constraining. Terror does not exist in isolation; it is spread for a purpose, generally to advance or publicize a cause or undermine public order as part of a political, ethnic, or religious struggle. It is this communicative aspect associated with 'terrorism' that leads to the old adage and analytic dead end: 'one man's terrorist is another man's freedom fighter." SLAUGHTER, Anne-Marie; BURKE-WHITE, William. An International Constitutional Moment. Harvard International Law Journal, Cambridge, vol. 43, no. 1, 2002, p. 12.

${ }_{29}$ SLAUGHTER, Anne-Marie; BURKE-WHITE, William. An International Constitutional Moment. Harvard International Law Journal, Cambridge, vol. 43, no. 1, 2002, p. 12. Tradução livre: "The fundamental issue at stake is not the desire to sow terror, but rather the types of targets attacked. Civilians must not be the deliberate targets of attack, under any circumstances, for any purpose." 
A defesa da constitucionalização do princípio da inviolabilidade civil está a depender da tomada de um próximo passo na concretização da individualização do Direito Internacional. Enquanto em um primeiro momento os diplomas internacionais enfatizam o dever dos governos de proteger seus próprios cidadãos, o grande desafio reside na implementação de mecanismos legais visando a transparência dos governos, e com isso permitindo sua responsabilização. Os mecanismos internacionais de repressão à violação do princípio da inviolabilidade civil funcionariam em sede complementar. No esforço contra o terrorismo, o esforço internacional na proteção deste princípio justificaria o ataque ao aparato material de Estados cuja conduta torne indistintas as ações governamentais e de entidades terroristas. Em suma, "nos últimos oitenta anos a inviolabilidade civil foi transformada de uma exceção retórica a um princípio básico em diversas áreas do direito internacional. Já é tempo de torná-la um princípio constitucional do sistema legal internacional."30

\subsection{A Escola Pluralista}

A Escola Pluralista enfatiza a importância de se distinguir as diferentes eras do constitucionalismo: antigo, moderno e pós-moderno. A característica distintiva dos trabalhos de autores identificados com esta escola é o engajamento crítico dispensado às concepções universalistas do Direito. Para os pluralistas, a tarefa de teorizar os arranjos constitucionais deve levar em conta o caráter contingente, contextualizado e constitutivo destas experiências. ${ }^{31}$ Tipicamente, a escola procura desconstruir os ideais universais contidos em propostas neokantianas para a normatização das relações internacionais, seja o liberalismo em sua vertente internacionalista, seja a percepção comunitária restrita ao âmbito nacional.

A ênfase do papel crítico da escola consiste em mapear a genealogia das experiências constitucionais e propor novos desenhos mais inclusivos, aptos a realçar e a reconhecer visões de mundo ofuscadas pela projeção universalista do constitucionalismo centrado no Estado-nação.

\footnotetext{
${ }^{30}$ SLAUGHTER, Anne-Marie; BURKE-WHITE, William. An International Constitutional Moment. Harvard International Law Journal, Cambridge, vol. 43, no. 1, 2002, p. 21. Tradução livre: “In the past eighty years civilian inviolability has been transformed from a rhetorical aside to a basic principle in many areas of international law. It is time to make it a constitutional principle of the international legal system."

31 WIENER, Antje; LANG, Anthony F.; TULLY, James; MADURO, Miguel Poiares; KUMM, Mattias. Global Constitutionalism: Human rights, democracy and the rule of law. Global Constitutionalism, Frankfurt am Main, vol. 1, no.1, 2012, p. 1-15.
} 
Ademais, a Escola Pluralista concentra parte de seus esforços na compreensão das dinâmicas de poder e autoridade em circunstâncias de interação entre instâncias normativas específicas.

O constitucionalismo global, na ótica pluralista, pode ser confrontado a partir de pelo menos dois eixos analíticos críticos: primeiro, a relação entre o estudo da História e o Direito revela uma narrativa histórica com imediatas implicações para a compreensão do papel do Direito Internacional; segundo, a genealogia do constitucionalismo vis-à-vis processos globais do colonialismo e imperialismo. A seção seguinte almeja empreender uma aproximação entre a crítica historiográfica e esta escola de pensamento.

\section{HISTORIOGRAFIA CRÍTICA, CONSTITUCIONALISMO GLOBAL E EMANCIPAÇÃO}

O exame da História tem o condão de esclarecer as possíveis conexões entre determinadas propostas de constitucionalização do direito global com visões unificadoras do tempo e espaço. A partir daí, desenvolvem-se ferramentas analíticas destinadas a questionar vertentes do pensamento jurídico que em geral desprezam o papel das práticas coloniais e imperiais na propagação dos ideais constitucionais localizados nas experiências de países Europeus. Os defensores das abordagens pós-coloniais e descoloniais argumentam no sentido da perpetuação, por outros meios e instituições, destas práticas, insistindo, em contrapartida, na necessidade de construção de novos arranjos constitucionais mais promissores, dialógicos e voltados para o mútuo reconhecimento da diversidade.

Num primeiro registro da relevância da história do Direito Internacional, o ato de recorrer ao passado pode estar associado a uma narrativa focada no progresso da disciplina, desde suas origens, passando por momentos cruciais e culminando na configuração contemporânea. Um conhecido exemplo desta inclinação à exaltação do progresso pode ser encontrado em Lassa Oppenheim ${ }^{32}$, segundo o qual a relevância do estudo da história do Direito Internacional consistiria em celebrar seus feitos e instruir os internacionalistas do presente. A história atestaria não apenas a formação da disciplina, mas também proporcionaria aos estudiosos e aplicadores das normas internacionais os meios para trabalharem com mais precisão e conhecimento, e com um claro papel de sua função social.

32 OPPENHEIM, Lassa. The Science of International Law: Its Task and Method. American Journal of International Law, Washington, v. 2, n. 2, 1908, p. 313-356. 
Portanto, a compreensão das origens dos institutos seria complementada pela articulação de uma ampla narrativa histórica que posicionaria a evolução do Direito Internacional lado a lado com a evolução da sociedade internacional. Registra Lassa Oppenheim que o trabalho do historiador é reconciliar, de forma harmoniosa, o passado e presente da disciplina, na qual “o grande historiador [...] deverá, em especial, trazer à luz o papel que certos Estados desempenharam no desenvolvimento vitorioso de certas regras e quais foram os interesses econômicos, políticos, humanitários, religiosos ou outros que ajudaram a estabelecer as presentes regras do direito internacional." ${ }^{33}$

Nestas trilhas, a história do Direito Internacional seria escrita a partir de uma investigação da procedência de uma dada regra ou instituto. 0 ato de compreensão de uma regra ou instituto é também uma inquirição sobre sua história em um sentido muito específico: a regra ou instituto chega aos nossos dias devido a um percurso evolutivo cujo começo é encontrado na esfera da política, e, por via de uma série de acertos, desacertos, avanços e retrocessos, culmina em sua inserção nos domínios do direito. A relação presente entre o profissional do direito internacional e a história do último apresenta natureza funcional, pois o acesso á história é motivada pela necessidade de compreensão de determinado aspecto no presente. Conceber a história neste sentido significa, no entender de David Kennedy, inquirir sobre a procedência dos elementos constitutivos da ordem jurídica internacional:

Um argumento sobre uma regra ou princípio, ou uma técnica institucional em direito internacional é quase sempre, também, um argumento sobre a história uma norma particular tem uma procedência enquanto direito [positivo] ao invés de [uma procedência] política, que tornou-se uma norma geral ao invés de específica, que veio, por meio da história, a situar-se de fora da história. ${ }^{34}$

Enquanto método de estudo de normas e institutos, a prática da história como procedência situa os internacionalistas na condição de instrumentos do direito, isto é, são intérpretes do direito que os precede, e que sempre está logo ali, pronto para ser identificado.

33 OPPENHEIM, Lassa. The Science of International Law: Its Task and Method. American Journal of International Law, Washington, v. 2, n. 2, 1908, p. 317. Tradução livre: The master-historian [...] will in special have to bring to light the part certain states have played in the victorious development of certain rules and what were the economic, political, humanitarian, religious, and other interests which have helped to establish the present rules of international law."

${ }^{34}$ KENNEDY, David. The Disciplines of International Law and Policy. Leiden Journal of International Law, Leiden, v. 12, n. 1, 1999, p. 88. Tradução livre: “[...] an argument about a rule or principle, or institutional technique in international law is almost always also an argument about history - that the particular norm proffered has a provenance as law rather than politics, has become general rather than specific, has come through history to stand outside history." 
Um efeito imediato desta abordagem é “[...] reforçar a fantasia de que aquele algo chamado 'direito internacional' teve e vem tendo uma presença contínua através das diferenças no tempo e lugar." 35 Há uma expectativa, uma crença - Kennedy usa a palavra 'fantasia' - inabalável no direito internacional como ele é, ou seja, a forma como ele chega até nós já é em si notável.

Idealizado como um verdadeiro projeto de direito, o risco imediato desta abordagem é negligenciar as implicações da prática historiográfica, os discursos identificáveis nas entrelinhas evolutivas dos institutos e regras, os processos de inclusão/exclusão que orbitam os domínios do direito - ocultados pela pretensão de neutralidade, universalidade e racionalidade. A narrativa histórica assume um conjunto de elementos em princípio constantes, amparados pela celebrada neutralidade do investigador em relação ao objeto investigado. Mais que uma história do sucesso do projeto que convencionamos chamar Direito das Gentes, a aproximação da construção histórica com a narrativa do progresso conta com aspectos poucos explorados pela historiografia tradicional. A bem-sucedida empreitada, um tanto quanto "eurocêntrica" na qualificação de Gathii $^{36}$, Anghie $^{37}$ e Koskenniemi ${ }^{38}$, pode ter encoberto - e persistindo nesta prática - processos de violência, exploração e exclusão ao longo de sua trajetória.

Neste sentido, trabalho notório foi conduzido por Martti Koskenniemi ${ }^{39}$ ao defender a tese central de sua obra The Gentle Civilizer of Nations, segundo a qual as narrativas de surgimento de uma sensibilidade para assuntos internacionais compõem projetos ou ideais liberais de eminentes pensadores desde meados do século XIX. As condições metodológicas para a execução desta empreitada foram discutidas pelo autor, constando-se, inicialmente, uma rejeição da concepção de evolução histórica linear, o que o leva a suspeitar de empreendimentos que pretendam relatar “[...] a grande história que pinta uma tela das 'épocas' que seguem umas às outras sob alguma lei metahistórica do funcionamento da 'cultura' ou 'poder' nos destinos de pessoas ou civilizações, padrões de criação, desenvolvimento e

\footnotetext{
${ }^{35}$ KENNEDY, David. The Disciplines of International Law and Policy. Leiden Journal of International Law, Leiden, v. 12, n. 1, 1999, p. 90. Tradução livre: "[...] reinforce the fantasy that something called 'international law' has had a continuous presence across differences in time and place."

${ }^{36}$ GATHII, James Thuo. International Law and Eurocentricity. The European Journal of International Law, Florença, vol. 9, no. 1, p. 184-211, 1998.

${ }_{37}$ ANGHIE, Antony. Decolonizing the Concept of "Good Governance". JONES, Branwen Gruffydd (ed.). Decolonizing International Relations. Lanham: Rowman \& Littlefield Publishers, 2006, p. 109-130; ANGHIE, Antony. Imperialism, Sovereignty and the Making of International Law. Cambridge: Cambridge University Press, 2004.

${ }_{38}$ KOSKENNIEMI, Martti. Histories of International Law: Dealing with Eurocentrism. Rechtsgeschichte, Frankfurt, vol. 19, p. 152-176, 2011.

39 KOSKENNIEMI, Martti. The Gentle Civilizer of Nations. The Rise and Fall of International Law 18701960. Cambridge: Cambridge University Press, 2001.
} 
declínio." 40 De um modo geral, tratam-se de histórias que reduzem as possibilidades de compreensão da história da disciplina.

Exemplo da tendência descrita por Koskenniemi, a agenda proposta pela vertente liberal da historiografia jusinternacionalista no contexto pós Guerra Fria revela, em fina adesão à visão linear da história, a promessa da expansão das democracias e da economia de mercado como os grandes pilares do desenvolvimento global e do progresso dos Estados e povos. A ideia de uma paz perpétua entre Estados democráticos, fomentada por instituições nacionais homogêneas e pela aproximação pelo comércio, teve sua mais difundida formulação com o filósofo Immanuel Kant, em fins dos setecentos. Contemporaneamente, internacionalistas neokantianos fizeram renascer tais ideais: a emergência de um direito à governança democrática, já no começo da década de 1990, defendida por Thomas Franck ${ }^{41}$ e as pesquisas de Anne-Marie Slaughter ${ }^{42}$ convergem para a postulação normativa de ideais liberais políticos, práticas de economia de mercado e instituições democráticas tanto em nível doméstico como em um projeto global mais amplo.

Note-se que esta abordagem historiográfica corrobora uma análise dos eventos internacionais pela qual os eventos do presente sucedem os eventos do passado. 0 modo como os eventos do passado são inseridos na narrativa não é problematizado; o que se verifica, sobretudo, é a simplificação, compressão e reconstrução do passado a fim de confecção de uma lista de fatores ligados às causas e às consequências de seu sucesso ou insucesso ou reflexos para o presente/futuro. A finalidade da investigação do passado, portanto, é aderir um evento já ocorrido a um evento presente, de modo que a preocupação central do historiador reside na identificação de uma tênue tradição de pensamento, resultando em uma prática à qual é atribuída normatividade.

A narrativa histórica tradicional, focada no progresso e na linearidade do registro historiográfico, exposta nos parágrafos anteriores, é confrontada em suas próprias bases por visões alternativas do papel da história na formação dos processos e dos atores engajados na

\footnotetext{
40 KOSKENNIEMI, Martti. The Gentle Civilizer of Nations. The Rise and Fall of International Law 18701960. Cambridge: Cambridge University Press, 2001, p. 6. Tradução livre: "The grand history that would paint a canvas of 'epochs' following each other under some metahistorical law about the workings of 'culture' or 'power' on the destinies of peoples or civilizations, patterns of creation, flourishing, and decline."

${ }^{41}$ FRANCK, Thomas M. The emerging right to democratic governance. American Journal of International Law, Washington, vol. 86, no. 1, 1992, p. 46-91.

${ }^{42}$ SLAUGHTER, Anne-Marie. International Law in a World of Liberal States. The European Journal of International Law, Florença, vol. 6, no. 3, 1995, p. 503-538.
} 
produção desta narrativa. A prática historiográfica, no entender de Michel-Rolph Trouillot ${ }^{43}$, implica grande poder: o poder de silenciar determinados eventos, ou mesmo qualificá-los como “não-eventos"44, assim produzindo a história oficial, composta por aqueles eventos dignos de registro e suficientemente relevantes para figurar na narrativa definitiva.

O historiador indiano Dipesh Chakrabarty, destacado membro do Subaltern Studies Group, não apenas partilha da crítica de Trouillot, mas propõe os alicerces de uma nova atitude intelectual perante a história. Reconhecendo, num primeiro momento, que os alicerces teóricos da historiografia indiana, até a década de 1970, eram compostos predominantemente por referencias europeus, isto é, localizados em uma determinada tradição, e, em seguida, sugerindo mecanismos responsáveis por sua universalidade e secularidade, termina por antever, na vertente historiográfica dominante - o historicismo - a consolidação definitiva da dominação colonial e imperial. Disso resulta uma história formada por estágios, com povos desenvolvidos e outros subdesenvolvidos, ou civilizados ou não-civilizados, compartimentados conforme os referenciais temporais e epistemológicos Europeus:

O historicismo, então, posiciona o tempo histórico como a medida da distância cultural (pelo menos quanto ao desenvolvimento institucional) que se acreditava existir entre o ocidente e o não-ocidente. Nas colônias, isto legitimou a ideia de civilização. Na Europa em si, isso possibilitou histórias da Europa nas quais a Europa era descrita como a primeira ocorrência do capitalismo, modernidade ou Iluminismo. ${ }^{45}$

Nestes termos, os projetos de constitucionalização do Direito Internacional que dispensem o exame crítico de seus precedentes, situando-os no cerce dos processos históricos de inclusão, exclusão, encobrimento ou distorção, parecem inaptos a perceber a diversidade e heterogeneidade da sociedade global e suas práticas contextualizadas e contingentes. Um

\footnotetext{
${ }^{43}$ TROUILLOT, Michel-Rolph. Silencing the Past: Power and the Production of History. Boston: Beacon Press, 1995.

${ }^{44}$ É este o caso da Revolução Haitiana, de 1790. Revolução liderada e realizado por escravos, em revolta ao jugo colonial francês, foi vista, em fins do século XVIII, como um não-evento histórico: uma Revolução de escravos não era propriamente uma "revolução", na medida em que não é orientada, primeiro, por um modus operandi europeu, e segundo, porque uma Revolução há de ser conduzida por homens livres, o que não é o caso da "Revolução" Haitiana. Destarte, um não evento-histórico. Conferir TROUILLOT, MichelRolph. Silencing the Past: Power and the Production of History. Boston: Beacon Press, 1995, p. 70-107.

45 CHAKRABARTY, Dipesh. Provincializing Europe: Postcolonial Thought and Historical Difference. Princeton: Princeton University Press, 2000, p. 7. Tradução livre: "Historicism thus posited historical time as a measure of the cultural distance (at least in institutional development) that was assumed to exist between the West and the non-West. In the colonies, it legitimated the idea o civilization. In Europe itself, it made possible completely internalist histories of Europe in which Europe was described as the site of the first occurence of capitalism, modernity, or Enlightenment."
} 
discurso constitucional único que faz as vezes de "história oficial” para o Século XXI termina por uniformizar as possibilidades discursivas, emancipatórias e construtivas que a prática constitucional pode revelar. Enfim, o modo como se aborda a história do Direito Internacional condiciona os termos dentro dos quais os debates doutrinários são inseridos.

Algumas vertentes jusinternacionalistas ilustram o tipo de sensibilidade realçada por Chakrabarty e Trouillot, e discutem o tipo de relação que pode ser traçada entre o Direito Internacional e os processos históricos do colonialismo e imperialismo. Dentre estas correntes, uma se destaca: o movimento ${ }^{46}$ denominado genericamente Third World Approaches to International Law (TWAIL) foi proposto por um grupo de internacionalistas engajados no exame da condição dos países em desenvolvimento ${ }^{47}$, na explicitação do viés ideológico da disciplina sua história “oficial” e suas instituições - e na proposição de modos alternativos de conceber o direito e as relações internacionais.

TWAIL congrega um conjunto de esforços investigativos lastreados por um ponto de partida comum: ao contrário das doutrinas tradicionais baseadas na convicção acadêmica de que o Direito Internacional é um projeto científico acabado e consolidado, os proponentes da teoria crítica típica de TWAIL trabalham com a ideia nuclear de que a disciplina jusinternacionalista é também um produto histórico-cultural contextualizado, atributo este que distingue as propostas críticas das formulações científico-pragmáticas.

Ademais, concebe-se tanto o Direito Internacional moderno quanto o constitucionalismo global como o resultado de uma ordem internacional desenhada por um número restrito de Estados ao longo de cinco séculos de relações assimétricas, violentas e opressoras. Conforme pontua Obiora Okafor $^{48}$, a ênfase conferida à questão da ordem implica por retirar a legitimidade e relevância das vozes que postulam a denunciação das injustiças e os desejos de emancipação de nações e povos do Terceiro Mundo. Outrossim, desqualificam-se as proposições

\footnotetext{
${ }^{46}$ Optamos pela designação genérica de movimento, uma vez que, sob este nome, a doutrina inclui uma série de abordagens de variadas estirpes e influências teóricas. Não deixa de existir, todavia, representativo grau de proximidade entre elas, o que justifica a nomenclatura genérica. Ver, a este respeito, PARMAR, Pooja. TWAIL: An Epistemological Inquiry. International Community Law Review, Columbia Britânica, vol. 10, p. 363-370, 2008.

${ }^{47}$ A expressão "Terceiro Mundo", presente na designação TWAIL, é mais comumente adotada, apesar de contestada por parte da doutrina. Cf: OKAFOR, Obiora Chinedu. Newness, Imperialism and International Legal Reform in our time: a TWAIL Perspective. Osgoode Hall Law Journal, York, vol. 43, no. 1 \& 2, p.171-191, 2005.

${ }^{48}$ OKAFOR, Obiora Chinedu. Newness, Imperialism and International Legal Reform in our time: a TWAIL Perspective. Osgoode Hall Law Journal, York, vol. 43, no. 1 \& 2, p.171-191, 2005.
} 
de alternativas ao status quo que não estejam formuladas e firmemente embasadas na tradição epistemológica dominante.

Ao tomar este referencial para sua agenda, o movimento demonstra uma vocação para o exame de questões aparentemente externas a uma disciplina jurídica, mas que, em um sentido histórico-cultural, tornam-se constitutivas e determinantes para as instituições jurídicas e, de forma não menos incisiva, para a sistematização do discurso jusinternacionalista. Okafor assim descreve o movimento nos seguintes termos:

Os acadêmicos TWAIL (ou 'TWAILers') estão solidamente unidos por compromisso ético partilhado engajado no esforço intelectual e prático de expor, reformar, ou até remover aqueles atributos do sistema jurídico internacional que ajudam a criar ou manter a injusta, desarrazoada e iníqua ordem global [...] trata-se de um comprometimento de centrar o resto ao invés do ocidente, para tanto tomando as vidas e experiências daqueles que se auto-identificam como Terceiro Mundo muito mais seriamente do que, em geral, vem sendo o caso. ${ }^{49}$

Contar as estórias não contadas do Direito Internacional, como realça Pooja Parmar ${ }^{50}$, é o objetivo primeiro daqueles que integram o movimento. Ao tratar de temas normalmente ausentes dos círculos acadêmicos conservadores, TWAIL agrega à sua pauta um esforço voltado para a elucidação das possíveis relações entre imperialismo, colonialismo, de um lado, e a construção do sistema jurídico internacional, de outro.

Variados estudos procuraram aprofundar os postulados de TWAIL, assim como contribuíram para seu fortalecimento epistêmico. Antony Anghie ${ }^{51}$ argumentou que o Direito Internacional moderno nasce do encontro colonial há cinco séculos, o que o leva a questionar os princípios da soberania e da igualdade soberana que tradicionalmente estruturam a disciplina. Por sua vez, Martti Koskenniemi ${ }^{52}$ sustentou a tese de que o Direito Internacional contemporâneo

\footnotetext{
49 OKAFOR, Obiora Chinedu. Newness, Imperialism and International Legal Reform in our time: a TWAIL Perspective. Osgoode Hall Law Journal, York, vol. 43, no. 1 \& 2, 2005, p. 176-177. Tradução livre: “[...] TWAIL scholars (or "TWAILers") are solidly united by a shared ethical commitment to the intellectual and practical struggle to expose, reform, or even retrench those features of the international legal system that help create or maintain the generally unequal, unfair, or unjust global order .[...] a commitment to centre the rest rather than merely the west, thereby taking the lives and experiences of those who have self-identified as Third World much more seriously than has generally been the case."

50 PARMAR, Pooja. TWAIL: An Epistemological Inquiry. International Community Law Review, Columbia Britânica, vol. 10, p. 363-370, 2008.

51 ANGHIE, Antony. Imperialism, Sovereignty and the Making of International Law. Cambridge: Cambridge University Press, 2004.

52 KOSKENNIEMI, Martti. The Gentle Civilizer of Nations. The Rise and Fall of International Law 18701960. Cambridge: Cambridge University Press, 2001; KOSKENNIEMI, Martti. Histories of International Law: Dealing with Eurocentrism. Rechtsgeschichte, Frankfurt am Main, vol. 19, p. 152-176, 2011.
} 
encontra sua gênese nos trabalhos de pensadores europeus do Século XIX comprometidos com a tarefa de "civilizar" as relações internacionais, evidenciando um componente eurocêntrico em sua gênese e modus operandi. E Nathaniel Berman ${ }^{53}$ problematizou a ambivalência do discurso histórico no qual operam poderosos artifícios retóricos, tal qual a invocação de valores universais ou de uma comunidade internacional, que potencialmente ofuscam as inerentes contradições da sociedade internacional, mas atestam a universalidade de determinados marcos temporais (1648 ou 1945, por exemplo).

De fato, ao trazer à tona a centralidade dos processos coloniais e imperiais enquanto condicionantes de muitos dos reveses da sociedade internacional, ao invés de simplesmente tratá-los como subprodutos remediáveis de uma ordem internacional em constante progresso, a teoria crítica de TWAIL faz coro com destacados ramos do constitucionalismo global. 0 conjunto de pensadores identificados com este ramo de pesquisa costuma destacar os graves problemas que resultam de se fazer tabula rasa das intricadas relações entre constitucionalismo e as práticas imperiais: o constitucionalismo articula um processo histórico específico, apoiado em formas descritivas e avaliativas dos diferentes níveis de amadurecimento social.

Deste modo, a identificação de um poder constituído (Europa, posteriormente também os EUA) em oposição às formas costumeiras (inferiores) de arranjos constitucionais nos demais povos, assim como a necessidade de um soberano ou a presença de técnicas modernas de governabilidade, são exemplos do standard constitucional diante do qual, no entender de James Tully, “[...] os processos discursivos globais foram predicados simultaneamente na modernização constitucional dos estados e nos seus projetos imperialistas desde o começo do período moderno."54

Diferentemente do que é sustentado pelos defensores da tese do fim da história, ou dos defensores de um novo momento para o Direito Internacional a partir da década de 1990 consoante exposto acerca da Escola Normativista -, os referenciais sugeridos por Tully parecem persistir nas formas contemporâneas do capitalismo financeiro, em instituições econômicas internacionais e nas iniciativas de governança global. Nos referenciais discutidos a respeito do constitucionalismo, cumpre enfatizar o alerta do autor: “[...] a democratização constitucional

53 BERMAN, Nathaniel. In the Wake of Empire. American University International Law Review, Washington, vol. 14, no. 6, 1999, p. 1515-1569.

54 TULLY, James. Modern Constitutional Democracy and Imperialism. Osgoode Hall Law Journal, York, vol. 46, 2008, p. 479. Tradução livre: "The world-process discursive formations have been predicated on both modernizing constitutional states and their imperializing projects simultaneously since the early modern period." 
de baixa intensidade das antigas colônias, e os regimes transnacionais quase constitucionais e os regimes internacionais que os superam se for necessário, agora provêm as bases políticas e legais para a nova fase do capitalismo global." 55

\section{CONCLUSÃO}

Alguns pontos merecem ser destacados, portanto sugerem uma reflexão mais ampla sobre os rumos do constitucionalismo global. A análise da Escola Funcionalista é direcionada para as estruturas institucionais já existentes, e isto é discutível ao menos sob dois aspectos. Em um tempo, questiona-se em que medida o funcionalismo não evoca uma narrativa histórica triunfalista, que atestaria as virtudes do presente e sua adequação para a regulação das relações internacionais. Em um segundo momento, a Escola parece conceber a sociedade internacional nos parâmetros de uma ideia de igualdade estritamente formal. Não confere importância aos processos coloniais e imperiais que, à luz de teorias críticas como TWAIL, parecem persistir, inclusive por meio das normas internacionais.

No tocante à Escola Normativa, um aspecto de maior projeção deve ser confrontado. 0 conteúdo material das normas tipicamente constitucionais, mesmo que pautado em temáticas de relevância indiscutível para a sociedade internacional - Direitos Humanos ou meio ambiente, por exemplo -, remete, em sua integralidade, à tradição constitucional moderna. A universalização do Direito Internacional tornou possível a universalização da dogmática constitucional moderna, seus postulados e estruturas normativas típicas. A leitura que a teoria crítica é capaz de fazer, tanto sob a perspectiva histórica quanto do Terceiro Mundo, atua no sentido de questionar as bases materiais do constitucionalismo moderno, e o faz defendendo uma conexão inescapável entre os processos coloniais e imperiais e a bem-sucedida trajetória dos postulados essenciais do Direito Internacional.

No esteio destes dois cenários, pelo menos dois riscos adicionais são identificados: o aumento das fontes de autoridade normativa não é acompanhado, assim se receia, pela indispensável accountability capaz de reverter a presunção da completa liberdade de atuação e nenhuma responsabilização. Realça-se a crescente despolitização de temas de relevância global

55 TULLY, James. Modern Constitutional Democracy and Imperialism. Osgoode Hall Law Journal, York, vol. 46, no. 3, 2008, p. 487. Tradução livre: “[...] the low intensity constitutional democratization of the former colonies, and the quasi-constitutional transnational and international legal regimes that override them if necessary, now provide the legal and political basis of a new phase of western imperialism." 
causada pela especialização funcional dos diversos ramos do Direito Internacional fragmentação. As lógicas subsistêmicas em confrontação aparentam não demonstrar a reverência necessária frente a qualquer parâmetro de aferição de legitimidade democrática.

À guisa de desfecho, algumas considerações restam ser tecidas sobre a Escola Pluralista. Um dos méritos desta Escola reside na proposição de bases constitucionais capazes de identificar manifestações legítimas de organização social e política que se situam fora dos padrões geralmente aceitos pela doutrina jusinternacionalista. Realçam os pluralistas que não existe um, mas sim vários constitucionalismos, de modo que as tentativas de uniformização das propostas de constitucionalização (uma única Constituição, com um único conteúdo atribuível para todos os povos) implicam por aproximar o constitucionalismo global da racionalidade própria do colonialismo e imperialismo: a uniformização de condutas e modos de vida sob os ditames de um molde central ou ideal.

Questões adicionais envolvem o desenvolvimento de técnicas de conciliação e diálogo permanente entre as várias tradições, de modo que sejam reconhecidas em seus próprios termos e referenciais. A historiografia crítica do Direito Internacional oferece, neste particular, bases para um produtivo enfrentamento dos marcos históricos ambivalentes e tomados irrestritamente por parte de significativa parcela dos representantes das escolas de pensamento aqui discutidas.

\section{REFERÊNCIAS}

ANGHIE, Antony. Imperialism, Sovereignty and the Making of International Law. Cambridge: Cambridge University Press, 2004.

BERMAN, Nathaniel. In the Wake of Empire. American University International Law Review, Washington, vol. 14, no. 6, p. 1515-1569, 1999.

CHAKRABARTY, Dipesh. Provincializing Europe: Postcolonial Thought and Historical Difference. Princeton: Princeton University Press, 2000.

DUNOFF, Jeffrey L.; TRACHTMAN, Joel P. A Functional Approach to International Constitutionalization. In: ___ (eds.) Ruling the World? Constitutionalism, International Law, and Global Governance. Cambridge: Cambridge University Press, 2009, p. 3-36.

DUNOFF, Jeffrey L.; TRACHTMAN, Joel P. (eds.). Ruling the World? Constitutionalism, International Law, and Global Governance. Cambridge: Cambridge University Press, 2009. 
FASSBENDER, Bardo. Rediscovering a Forgotten Constitution: Notes on the Place of the UN Charter in the International Legal Order. In: DUNOFF, Jeffrey L.; TRACHTMAN, Joel P. (eds.). Ruling the World? Constitutionalism, International Law, and Global Governance. Cambridge: Cambridge University Press, p. 133-147, 2009.

FISCHER-LESCANO, Andreas; TEUBNER, Gunther. Regime Collisions: the vain search for legal unity in the fragmentation of global law. Michigan Journal of International Law, Michigan, vol. 25, no. 4, p. 999-1046, 2004.

FRANCK, Thomas M. The emerging right to democratic governance. American Journal of International Law, Washington, vol. 86, no. 1, p. 46-91, 1992.

GATHII, James Thuo. International Law and Eurocentricity. The European Journal of International Law, Florença, vol. 9, no. 1, p. 184-211, 1998.

KENNEDY, David. The Disciplines of International Law and Policy. Leiden Journal of International Law, Leiden, v. 12, n. 1, p. 9-133, 1999.

KOSKENNIEMI, Martti. Histories of International Law: Dealing with Eurocentrism.

Rechtsgeschichte, Frankfurt, vol. 19, p. 152-176, 2011.

KOSKENNIEMI, Martti. The Gentle Civilizer of Nations. The Rise and Fall of International Law 1870-1960. Cambridge: Cambridge University Press, 2001.

LOUGHLIN, Martin; WALKER, Neil. Introduction. (eds.). The Paradox of Constitutionalism: Constituent Power and Constitutional Form. Oxford: Oxford University Press, p. 1-7, 2007.

OKAFOR, Obiora Chinedu. Newness, Imperialism and International Legal Reform in our time: a TWAIL Perspective. Osgoode Hall Law Journal, York, vol. 43, no. 1 \& 2, p.171-191, 2005.

OPPENHEIM, Lassa. The Science of International Law: Its Task and Method. American Journal of International Law, Washington, v. 2, n. 2, p. 313-356, 1908.

PARMAR, Pooja. TWAIL: An Epistemological Inquiry. International Community Law Review, Columbia Britânica, vol. 10, p. 363-370, 2008.

PAULUS, Andreas L. The International Legal System as a Constitution. In: DUNOFF, Jeffrey L.; TRACHTMAN, Joel P (eds.). Ruling the World? Constitutionalism, International Law, and Global Governance. Cambridge: Cambridge University Press, p. 69-109, 2009.

PETERS, Anne. The Merits of Global Constitutionalism. Indiana Journal of Global Legal Studies, Bloomington, vol. 16, no. 2, p. 397-411, 2009. 


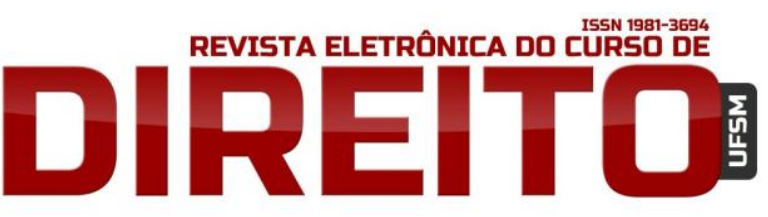

CONSTITUCIONALISMO ALÉM DO ESTADO: PERSPECTIVAS HISTÓRICAS E DEMANDAS EMANCIPATÓRIAS

HENRIQUE WEIL AFONSO THALES CAVALCANTI CASTRO

PETERS, Anne. Compensatory Constitutionalism: The Function and Potential of Fundamental International Norms and Structures. Leiden Journal of International Law, Leiden, vol. 19, no. 3, p. 579-610, 2006.

SLAUGHTER, Anne-Marie; BURKE-WHITE, William. An International Constitutional Moment. Harvard International Law Journal, Cambridge, vol. 43, no. 1, p. 1-21, 2002.

TRIBUNAL PENAL INTERNACIONAL PARA A EX-IUGOSLÁVIA (TPII). Prosecutor v. Martić, Case No. IT-95-11, Decisão de 8 de março de 1996. Disponível em:

<http://www.icty.org/case/martic/4>. Acesso em: 25 ago de 2014.

TROUILLOT, Michel-Rolph. Silencing the Past: Power and the Production of History. Boston: Beacon Press, 1995.

TULLY, James. Strange Multiplicity. Constitutionalism in an Age of Diversity. Cambridge:

Cambridge University Press, 1995.

TULLY, James. Modern Constitutional Democracy and Imperialism. Osgoode Hall Law Journal, York, vol. 46, p. 461-493, 2008.

WIENER, Antje. Global Constitutionalism. Oxford Bibliographies Online, 2012. Disponível em: <http://www.oxfordbibliographies.com/view/document/obo-9780199743292/obo9780199743292-0092.xml>. Acesso em: 31 ago. 2014.

WIENER, Antje; LANG, Anthony F.; TULLY, James; MADURO, Miguel Poiares; KUMM, Mattias. Global Constitutionalism: Human rights, democracy and the rule of law. Global Constitutionalism, Frankfurt am Main, vol. 1, no.1, p. 1-15, 2012.

Recebido em: 25/09/2015 / Aprovado em: 04/11/2015. 